\title{
MMSE Subscale Scores as Useful Predictors of AD Conversion in Mild Cognitive Impairment
}

This article was published in the following Dove Press journal:

Neuropsychiatric Disease and Treatment

\author{
Young Min Choe $\mathbb{D}^{1,2}$ \\ Boung Chul Lee (iD) 2,3 \\ Ihn-Geun Choi iD ${ }^{4}$ \\ Guk-Hee Suh (iD) 1,2 \\ Dong Young Lee iD ${ }^{5}$ \\ Jee Wook Kim (D) ${ }^{1,2}$ \\ On behalf of the \\ Alzheimer's Disease \\ Neuroimaging Initiative \\ 'Department of Neuropsychiatry, Hallym \\ University Dongtan Sacred Heart \\ Hospital, Hwaseong, Gyeonggi, Republic \\ of Korea; ${ }^{2}$ Department of Psychiatry, \\ Hallym University College of Medicine, \\ Chuncheon, Republic of Korea; \\ ${ }^{3}$ Department of Neuropsychiatry, Hallym \\ University Hangang Sacred Heart \\ Hospital, Seoul, Republic of Korea; \\ ${ }^{4}$ Department of Psychiatry, Seoul W \\ Psychiatric Office, Seoul, Republic of \\ Korea; ${ }^{5}$ Department of Neuropsychiatry, \\ Seoul National University Hospital, Seoul, \\ Republic of Korea
}

Purpose: This study was performed to examine the usefulness of subscores on the MiniMental State Examination (MMSE) for predicting the progression of Alzheimer's disease (AD) dementia in individuals with mild cognitive impairment (MCI).

Patients and Methods: A total of 306 MCI individuals in the Alzheimer's Disease Neuroimaging Initiative database were included in the study. Standardized clinical and neuropsychological tests were performed at baseline and at 2-year follow-up. Logistic regression analysis was conducted to examine the MMSE total and subscale scores to predict progression to AD dementia in MCI individuals.

Results: The MMSE total score and the MMSE memory, orientation, and construction subscores were inversely associated with AD progression after controlling for all potential confounders; MMSE attention and language subscores were not correlated with AD progression. The MMSE delayed recall score among the MMSE memory subscores and the MMSE time score among the orientation subscores, especially week and day, were inversely associated with $\mathrm{AD}$ progression; the MMSE immediate recall and place scores were not correlated with progression.

Conclusion: Our findings suggest that the MMSE memory, orientation, and construction subscores, which are simple and readily available clinical measures, could provide useful information to predict $\mathrm{AD}$ dementia progression in MCI individuals in practical clinical settings.

Keywords: mini-mental state examination, MMSE, mild cognitive impairment, MCI, Alzheimer's disease, AD, memory, orientation, construction

\section{Introduction}

Mild cognitive impairment (MCI) is classified as a transitional state between normal aging and mild dementia. ${ }^{1}$ Longitudinal studies have found that the annual risk of conversion from MCI to probable Alzheimer's disease (AD) was $10-15 \%$. $^{2,3}$ Due to the high risk of conversion to AD, MCI has become a major concern for early detection of $\mathrm{AD}$ to initiate preventive measures. However, it is difficult to predict progression from MCI to $\mathrm{AD}$, and a significant portion of MCI individuals remain stable or return to a normal cognitive state. ${ }^{4,5}$

A number of studies have attempted to identify useful predictors of conversion from MCI to AD, including a number of neuropsychological markers, ${ }^{6-8}$ neuroimaging biomarkers, ${ }^{9-11}$ genetic markers, ${ }^{12-14}$ and biochemical markers ${ }^{15-18}$ alone and in various combinations. ${ }^{19,20}$ Especially, neuroimaging biomarkers, including magnetic resonance imaging $(\mathrm{MRI})$ and positron emission tomography (PET) with fluorodeoxyglucose and beta amyloid tracers, showed high sensitivity and
Correspondence: Jee Wook Kim Department of Neuropsychiatry, Hallym University Dongtan Sacred Heart

Hospital, 7 Keunjaebong-gil, Hwaseong-si, Gyeonggi-do 18450, Republic of Korea

Tel +82 3I 80862340

Fax +823180862029

Email kimakins@hanmail.net 
specificity. ${ }^{21}$ However, they are expensive, are feasible only in specialized medical centers, ${ }^{22}$ and are not appropriate for use in primary care settings, routine bedside check-ups, preventive health care settings, and large community-based studies.

It is important to identify a relatively simple, timesaving, and cost-effective predictor of $\mathrm{AD}$ conversion that can be easily used in a practical clinical setting. Previous studies suggested that the Mini-Mental State Examination (MMSE), ${ }^{23}$ Clinical Dementia Rating (CDR) Sum of Boxes (CDR-SB), ${ }^{24}$ and CDR orientation score $^{25}$ were good candidates for such a simple clinical predictor of $\mathrm{AD}$ progression. In this study, we examined the use of specific domains of the MMSE as potential markers of $\mathrm{AD}$ conversion. The MMSE has long been widely used as a tool to screen for cognitive impairment. ${ }^{26}$ The MMSE total score comprises subscores representing each cognitive domain: memory, orientation, attention, language, and construction. Several studies have reported the usefulness of MMSE subscores. More rapid decline in the MMSE language subscore was observed in both language and behavioral variants of frontotemporal degeneration, ${ }^{27}$ and MMSE subscores were helpful in differentiating between dementia with Lewy bodies and $\mathrm{AD}^{28}$

Not all domains of cognitive function deteriorate at the same time during the period of early cognitive changes in $\mathrm{AD}$. In general, the decline of non-memory areas and related functions follow decline of episodic memory. ${ }^{29}$ Therefore, specific MMSE domains other than memory may be useful for predicting conversion to $\mathrm{AD}$ in $\mathrm{MCI}$ individuals. However, little is known about this issue. This study was performed to investigate the usefulness of MMSE total and subscale scores for predicting $A D$ dementia progression within a 2-year follow-up period in elderly individuals with MCI.

\section{Materials and Methods}

\section{Study Design and Participants}

Demographic information and clinical data used in this study were obtained from the Alzheimer's Disease Neuroimaging Initiative 1 (ADNI-1) database (http:// adni.loni.usc.edu) on 2 February 2015. The ADNI was launched in 2003 as a public-private partnership led by Principal Investigator Michael W. Weiner, MD. The primary goal of ADNI has been to test whether serial MRI, PET, and other biological markers along with clinical and neuropsychological assessments can be combined to measure the progression of $\mathrm{MCI}$ and early $\mathrm{AD}$. For up-to-date information, see http://www.adni-info.org. The study protocol was approved by the institutional review board of each participating site, and written informed consent was obtained from all participants. The complete list of ADNI sites' IRBs can be found at:

http://adni.loni.usc.edu/wp-content/uploads/how to apply/ADNI_Acknowledgement_List.pdf

From the ADNI-1 cohort, this study included 306 participants who were MCI at baseline evaluation and had at least one 2-year follow-up visit. All individuals with MCI met the current consensus criteria for amnestic $\mathrm{MCI}{ }^{30}$ a memory complaint by the subject or their representative, objective memory loss measured by educationadjusted scores on the Wechsler Memory Scale Logical Memory II, absence of significant levels of impairment in other cognitive domains, essentially preserved activities of daily living, and an absence of dementia. All of the MCI subjects had total MMSE scores of 24-30 and a CDR of 0.5 . Details of inclusion and exclusion criteria for participants can be found at http://www.adni-info.org.

\section{Baseline and Follow-Up Assessments}

All participants underwent a standardized clinical evaluation based on the study protocol. Neurological assessments included the Alzheimer Disease Assessment ScaleCognitive (ADAS-Cog), ${ }^{31}$ MMSE, and CDR-SB. The MMSE scores were divided into subscores for orientation, memory, attention, language, and construction. The data at baseline and 24 months were used to determine AD conversion, and subjects were considered to have progressed to AD if they met the National Institute of Neurological and Communicative Disorders and Stroke-Alzheimer's Disease and Related Disorders (NINCDS-ADRDA) criteria for $\mathrm{AD}^{32}$

\section{Statistical Analysis}

The subjects were divided into two groups according to the clinical state at the 2-year follow-up evaluation: those who progressed to AD dementia (MCIp group) and those who did not (MCInp group). Between-group comparisons for baseline continuous data, including demographic and clinical data, were performed using two-tailed $t$-tests. Baseline categorical data were analyzed by chi-square test or Fisher's exact test. Logistic regression analysis was performed to examine the ability of MMSE total or subscale scores to predict progression to AD dementia in 
MCI individuals. For each analysis of the association between MMSE and progression to AD dementia, three models were tested for stepwise control of potential confounders. The first model did not include any covariates; the second model included age, gender, and education as covariates; and the third model included all potential covariates: age, gender, education, and CDR-SR. In all analyses, two-tailed $p$-values $<0.05$ were taken to indicate statistical significance.

\section{Results}

\section{Presence of AD Progression Within 2- Year Follow-Up Period}

All subjects $(\mathrm{n}=306)$ were diagnosed with MCI at baseline assessments. After a 2-year follow-up, 111 (36.3\%) had progressed to $\mathrm{AD}$ dementia (MCIp group), whereas the remaining 195 (63.7\%) had not (MCInp group) (Table 1).

\section{Baseline Characteristics of AD Progression and Non-Progression Groups}

The baseline demographics and clinical characteristics of the MCIp and MCInp groups are shown in Table 1. There were no significant differences between the two groups with regard to age, sex, education, and CDR global score. The MCIp group had significantly higher CDR-SB scores and lower MMSE total and some MMSE subscores (memory, orientation, and construction) than the MCInp group. In terms of the MMSE memory subscore, the MCIp group showed significantly lower MMSE delayed recall scores than the MCInp group, but there was no significant difference in the MMSE immediate recall score between the two groups. With regard to the MMSE orientation subscore, there was a significant difference between the two groups in time subscore, but not in the place subscore. Among the MMSE time subscores, the week score of the MCIp group was significantly lower $(p=0.008)$ compared to those of the MCInp group, and the time score was almost significantly lower $(\mathrm{p}=0.054)$. However, there were no significant differences in other orientation subscale scores between the two groups.

\section{Association of MMSE Total and Orientation Score with AD Progression}

As shown in Table 2, MMSE total score and memory, orientation, and construction subscale scores showed significant negative associations with AD progression after controlling for potential confounding variables, whereas attention and language score showed no such relations. Table 3 shows that the delayed recall score in the memory subscale scores and the time score in the orientation subscale scores were negatively associated with $\mathrm{AD}$ progression, whereas the immediate recall and place scores showed no such relations.

To assess the relationships of time subscale scores with AD progression, a series of logistic regression analyses were conducted in four steps (Table 4). In the first step, we tested one-item models: among the five models, the MMSE time-week (MMSE-W) model was statistically significant. In the second step, we tested two-item models, which included the MMSE-W model, and found that only the MMSE time-week and day (MMSE-WD) model was significant. In the third step, MMSE time-season, week, and day (MMSE-SWD) and MMSE time-month, week, and day (MMSE-MWD) were significant among the threeitem models that included MMSE-WD. In the fourth step, all four-item models that included MMSE time-SWD or -MWD were significant.

\section{Discussion}

This study was performed to investigate whether specific MMSE domains are useful predictors of AD conversion in MCI individuals through a 2-year follow-up. This is the first longitudinal study using MMSE subscores to determine AD conversion among individuals with MCI. Our results showed that MMSE subscores for orientation and construction, as well as for memory, are useful predictors of conversion from MCI to AD.

As $\mathrm{AD}$ is characterized by a long preclinical period in which defects in episodic memory can be detected, ${ }^{33}$ episodic memory decline is a well-known predictor of $\mathrm{AD}$ progression. ${ }^{34}$ In accordance with these results, we showed that the MMSE delayed recall subscore predicted conversion to AD. Furthermore, our results showed that the MMSE time orientation subscore could be useful for predicting AD conversion in MCI. These results were consistent with a previous study showing that memory and temporal orientation were initial MMSE items that were lost during the course of AD. ${ }^{35}$ Another study also demonstrated that the MMSE orientation for time predicted cognitive decline in elderly people. ${ }^{36}$

In terms of the usefulness of the MMSE orientation score, one possible interpretation is that orientation consists of multiple cognitive domains, including attention 
Table I Baseline Characteristics of the Amnestic $\mathrm{MCl}$ Group That Did Not Progress to AD Dementia (MCInp Group) and the Group That Did (MClp Group) at 2-Year Follow-Up $(n=306)$

\begin{tabular}{|c|c|c|c|}
\hline & $\begin{array}{l}\text { MCInp Group } \\
(n=195)\end{array}$ & $\begin{array}{l}\text { MClp Group } \\
(n=I I I)\end{array}$ & p-value \\
\hline Age (Years) & $74.75 \pm 7.39$ & $74.77 \pm 7.07$ & $0.984^{\dagger}$ \\
\hline Sex (Male/ Female) & $\begin{array}{l}127(65.13) / 68 \\
(34.87)\end{array}$ & $\begin{array}{l}69(62.16) / 42 \\
(37.84)\end{array}$ & $0.603^{\ddagger}$ \\
\hline Education (Years) & $15.79 \pm 2.97$ & $15.72 \pm 2.85$ & $0.83 \mathrm{I}^{\dagger}$ \\
\hline CDR global score & 0.5 & 0.5 & \\
\hline CDR sum of box & $1.40 \pm 0.70$ & $1.84 \pm 1.00$ & $<0.00 \mathrm{I}^{\dagger}$ \\
\hline MMSE total score & $27.42 \pm 1.72$ & $26.62 \pm 1.61$ & $<0.00 \mathrm{I}^{\dagger}$ \\
\hline \multicolumn{4}{|l|}{ MMSE subscale score } \\
\hline $\begin{array}{l}\text { MMSE memory } \\
\text { score } \\
\text { Immediate recall } \\
\text { Delayed recall }\end{array}$ & $\begin{array}{l}4.96 \pm 1.02 \\
2.96 \pm 0.20 \\
2.01 \pm 1.00\end{array}$ & $\begin{array}{l}4.50 \pm 1.10 \\
2.98 \pm 0.19 \\
1.51 \pm 1.08\end{array}$ & $\begin{array}{l}<0.001^{\dagger} \\
0.323^{\dagger} \\
<0.001^{\dagger}\end{array}$ \\
\hline $\begin{array}{l}\text { MMSE orientation } \\
\text { score }\end{array}$ & $9.16 \pm 1.00$ & $8.86 \pm 1.03$ & $0.012^{\dagger}$ \\
\hline Time score & $4.64 \pm 0.66$ & $4.39 \pm 0.75$ & $0.003^{\dagger}$ \\
\hline Year 0/I & $\begin{array}{l}5(2.56) / 190 \\
(97.44)\end{array}$ & $\begin{array}{l}2(1.80) / 109 \\
(98.20)\end{array}$ & $1.000 *$ \\
\hline Month 0/I & $\begin{array}{l}3(1.54) / 192 \\
(98.46)\end{array}$ & $\begin{array}{l}4(3.60) / 107 \\
(96.40)\end{array}$ & $0.260 *$ \\
\hline Week 0/I & $\begin{array}{l}13(6.67) / 182 \\
(93.33)\end{array}$ & $\begin{array}{l}18(16.22) / 93 \\
(83.78)\end{array}$ & $0.008^{\dagger}$ \\
\hline Day 0/I & $\begin{array}{l}33(16.92) / 162 \\
(83.08)\end{array}$ & $\begin{array}{l}29(26.13) / 82 \\
(73.87)\end{array}$ & $0.054^{\dagger}$ \\
\hline Season 0/I & $\begin{array}{l}17(8.72) / 178 \\
(91.28)\end{array}$ & $\begin{array}{l}15(13.51) / 96 \\
(86.49)\end{array}$ & $0.187^{\dagger}$ \\
\hline Place score & $4.52 \pm 0.68$ & $4.47 \pm 0.69$ & $0.503^{\dagger}$ \\
\hline Hospital 0/I & $\begin{array}{l}20(10.26) / 175 \\
(89.74)\end{array}$ & $\begin{array}{l}10(9.01) / 101 \\
(90.99)\end{array}$ & $0.724^{\dagger}$ \\
\hline Floor 0/I & $\begin{array}{l}39(15.38) / 165 \\
(84.62)\end{array}$ & $\begin{array}{l}25(22.52) / 86 \\
(77.48)\end{array}$ & $0.118^{\dagger}$ \\
\hline City $0 / 1$ & $\begin{array}{l}15(7.69) / 180 \\
(92.31)\end{array}$ & $\begin{array}{l}3(2.70) / 108 \\
(97.30)\end{array}$ & $0.082 *$ \\
\hline Area $0 / 1$ & $\begin{array}{l}26(13.33) / 169 \\
(86.67)\end{array}$ & $\begin{array}{l}20(\mid 8.02) / 9 \mid \\
(81.98)\end{array}$ & $0.270^{\dagger}$ \\
\hline State $0 / 1$ & $\begin{array}{l}2(1.03) / 193 \\
(98.97)\end{array}$ & $\begin{array}{l}1(0.90) / 110 \\
(99.10)\end{array}$ & $1.000 *$ \\
\hline $\begin{array}{l}\text { MMSE attention } \\
\text { score }\end{array}$ & $4.73 \pm 0.79$ & $4.74 \pm 0.72$ & $0.908^{\dagger}$ \\
\hline $\begin{array}{l}\text { MMSE language } \\
\text { score }\end{array}$ & $8.35 \pm 0.57$ & $8.35 \pm 0.57$ & $0.969^{\dagger}$ \\
\hline Naming $0 / 1 / 2$ & $\begin{array}{l}0(0) / 0(0) / 195 \\
(100)\end{array}$ & $\begin{array}{l}0(0) / 1(0.90) / \\
110(99.10)\end{array}$ & $0.363^{*}$ \\
\hline
\end{tabular}

(Continued)
Table I (Continued).

\begin{tabular}{|c|c|c|c|}
\hline & $\begin{array}{l}\text { MClnp Group } \\
(n=195)\end{array}$ & $\begin{array}{l}\text { MClp Group } \\
(n=I I I)\end{array}$ & p-value \\
\hline Command $0 / 1 / 2 / 3$ & $\begin{array}{l}0(0) / 0(0) / 26 \\
(13.33) / 169 \\
(86.67)\end{array}$ & $\begin{array}{l}0(0) / 0(0) / 11 \\
(9.91) / 100 \\
(90.09)\end{array}$ & $0.467^{*}$ \\
\hline Repetition 0/I & $\begin{array}{l}38(19.45) / 157 \\
(80.51)\end{array}$ & $\begin{array}{l}23(20.72) / 88 \\
(72.28)\end{array}$ & $0.882^{\ddagger}$ \\
\hline Reading $0 / 1$ & $0(0) / 195(100)$ & $\begin{array}{l}I(0.90) / 110 \\
(99.10)\end{array}$ & $0.363^{*}$ \\
\hline Writing $0 / 1$ & $\begin{array}{l}4(2.05) / / 91 \\
(97.95)\end{array}$ & $\begin{array}{l}3(2.70) / 108 \\
(97.30)\end{array}$ & $0.707^{*}$ \\
\hline $\begin{array}{l}\text { MMSE construction } \\
\text { score } 0 / 1\end{array}$ & $\begin{array}{l}17(8.72) / 178 \\
(91.28)\end{array}$ & $\begin{array}{l}21(18.92) / 90 \\
(81.08)\end{array}$ & $0.012^{\ddagger}$ \\
\hline
\end{tabular}

Notes: Data are presented as mean \pm SD or number $(\%) .{ }^{\dagger}$ Student's $t$-test; ${ }^{\ddagger}$ chisquare test; *Fisher's exact test.

Abbreviations: $\mathrm{MCl}$, mild cognitive impairment; $A D$, Alzheimer's disease; $C D R$, Clinical Dementia Rating; MMSE, Mini-Mental State Examination.

and visuospatial perception as well as memory. ${ }^{25}$ Episodic memory impairment is the earliest symptom of $\mathrm{AD}$, followed by attention and visuospatial dysfunction. ${ }^{37}$ Individuals with MCI already have reduced memory performance, ${ }^{38}$ so examination of orientation, which contains more information in addition to memory, may be more effective compared to examination of memory alone. In terms of orientation-related neural substrates, a clinicopathological study reported that both temporal and spatial disorientation in $\mathrm{AD}$ were related to neurofibrillary tangle densities in the hippocampus, superior parietal, and posterior cingulate cortex. ${ }^{39}$ In contrast to this result, we found that place orientation could not predict AD conversion, whereas time orientation showed predictive capability. A previous PET study showed differences in the biological underpinnings of time and place orientation: time orientation was associated with the rate of glucose metabolism in the posterior cingulate gyri and right middle temporal gyrus, whereas place orientation was correlated with glucose metabolism in the right posterior cingulate gyrus. ${ }^{40}$ Our results also suggested that time orientation may have specific neural substrates that are distinct from those for place orientation.

We found that the MMSE construction score was a valid predictor of $\mathrm{AD}$ conversion. The construction subscore was obtained using an interlocking pentagon copying item, which is given a maximum score of 1 point. The pentagon copying test is known to be an effective method for distinguishing between patients with dementia with 
Table 2 Results of Multiple Logistic Regression Analysis to Assess the Relationships of MMSE Total and Subscale Scores with AD Progression at 2-Year Follow-Up in Individuals with $\mathrm{MCl}$

\begin{tabular}{|c|c|c|}
\hline & \multicolumn{2}{|c|}{ AD Progression at Two-Year Follow-Up } \\
\hline & OR (95\% CI) & $P$ value \\
\hline \multicolumn{3}{|c|}{ MMSE total score } \\
\hline Model I & $0.758(0.657$ to 0.874$)$ & $<0.001$ \\
\hline Model 2 & 0.754 (0.652 to 0.872$)$ & $<0.001$ \\
\hline Model 3 & 0.787 (0.677 to 0.914$)$ & 0.002 \\
\hline \multicolumn{3}{|c|}{ MMSE subscale score } \\
\hline \multicolumn{3}{|c|}{ Memory score } \\
\hline Model I & $0.663(0.531$ to 0.829$)$ & $<0.001$ \\
\hline Model 2 & $0.662(0.530$ to 0.828$)$ & $<0.001$ \\
\hline Model 3 & $0.673(0.534$ to 0.847$)$ & 0.001 \\
\hline \multicolumn{3}{|c|}{ Orientation score } \\
\hline Model I & $0.750(0.597$ to 0.943$)$ & 0.014 \\
\hline Model 2 & 0.751 ( 0.595 to 0.948$)$ & 0.016 \\
\hline Model 3 & 0.827 (0.649 to 1.055$)$ & 0.127 \\
\hline \multicolumn{3}{|c|}{ Attention score } \\
\hline Model I & 1.018 (0.75- to 1.382$)$ & 0.908 \\
\hline Model 2 & 1.017 (0.745 to I.388) & 0.917 \\
\hline Model 3 & $1.037(0.750$ to 1.434$)$ & 0.826 \\
\hline \multicolumn{3}{|c|}{ Language score } \\
\hline Model I & $1.008(0.668$ to 1.523$)$ & 0.969 \\
\hline Model 2 & 1.014 (0.670 to I.534) & 0.948 \\
\hline Model 3 & 0.972 (0.633 to 1.493$)$ & 0.898 \\
\hline \multicolumn{3}{|c|}{ Construction score } \\
\hline Model I & $0.409(0.206$ to 0.814$)$ & 0.011 \\
\hline Model 2 & $0.405(0.203$ to $0.8 \mathrm{II})$ & 0.011 \\
\hline Model 3 & $0.382(0.186$ to 0.783$)$ & 0.009 \\
\hline
\end{tabular}

Notes: Model I did not include any covariates. Model 2 included age, sex, and education as covariates. Model 3 included age, sex, education, and CDR-SB score as covariates.

Abbreviations: $\mathrm{OR}$, odds ratio; $\mathrm{Cl}$, confidence interval.

Lewy bodies from those with $\mathrm{AD} .^{41}$ Our results demonstrated the possibility of using the pentagon copying test as a screening tool for $\mathrm{AD}$ conversion. To complement the crude scoring method ( $0 / 1$ score) and increase the ability to identify subtle differences, further studies using a wider range of scoring methods, eg, Bender-Gestalt test (0-4point scores) or the Qualitative Scoring MMSE Pentagon Test (0-13-point scores), ${ }^{42}$ should be performed in the future.

The use of the MMSE subscores has a number of merits, including simplicity of administration and ease of
Table 3 Results of Multiple Logistic Regression Analysis to Assess the Relationships of MMSE Memory and Orientation Subscale Scores with AD Progression at 2-Year Follow-Up in Individuals with $\mathrm{MCl}$

\begin{tabular}{|c|c|c|}
\hline & \multicolumn{2}{|c|}{ AD Progression at Two-Year Follow-Up } \\
\hline & OR $(95 \% \mathrm{CI})$ & $P$ value \\
\hline \multicolumn{3}{|c|}{ MMSE memory-immediate recall score } \\
\hline Model I & 2.060 (0.470 to 9.026$)$ & 0.338 \\
\hline Model 2 & 2.082 (0.467 to 9.289$)$ & 0.337 \\
\hline Model 3 & 2.090 (0.485 to 8.998$)$ & 0.322 \\
\hline \multicolumn{3}{|c|}{ MMSE memory-delayed recall score } \\
\hline Model I & 0.639 (0.509 to 0.803$)$ & $<0.001$ \\
\hline Model 2 & 0.639 (0.509 to 0.803$)$ & $<0.001$ \\
\hline Model 3 & $0.648(0.512$ to 0.820$)$ & $<0.001$ \\
\hline \multicolumn{3}{|c|}{ MMSE orientation-time score } \\
\hline Model I & $0.612(0.439$ to 0.855$)$ & 0.004 \\
\hline Model 2 & 0.615 (0.439 to 0.860$)$ & 0.004 \\
\hline Model 3 & 0.689 (0.485 to 0.980$)$ & 0.038 \\
\hline \multicolumn{3}{|c|}{ MMSE orientation-place score } \\
\hline Model I & $0.890(0.635$ to 1.249$)$ & 0.501 \\
\hline Model 2 & $0.900(0.639$ to 1.268$)$ & 0.548 \\
\hline Model 3 & $0.983(0.689$ to 1.403$)$ & 0.926 \\
\hline
\end{tabular}

Notes: Model I did not include any covariates. Model 2 included age, sex, and education as covariates. Model 3 included age, sex, education, and CDR-SB score as covariates.

Abbreviations: $\mathrm{OR}$, odds ratio; $\mathrm{Cl}$, confidence interval.

use and interpretation of the results. In addition, it is possible to obtain information about $\mathrm{AD}$ conversion through existing routine tests without additional tests. However, this study also has several limitations. The MMSE score is known to be highly affected by age, sex, and education. ${ }^{43,44}$ In general assessments, the normality of the MMSE total score was determined by using age-, sex-, and education-adjusted normative data; unfortunately, no such norms are available for the subscores of MMSE. However, these factors are unlikely to have affected the results of this study because we found no significant differences in age, sex, or education level between the MCIp and MCInp groups, and the results remained significant after controlling for age, sex, and education. Another issue was that the NINCDS-ADRDA criteria were used to determine AD conversion, instead of using biomarkers of $\mathrm{AD}$. The objective of the present study was to investigate predictors of $\mathrm{AD}$ conversion in a practical clinical setting, so we excluded these biomarkers. The importance of biomarkers in $\mathrm{AD}$ research is 
Table 4 Results of Multiple Logistic Regression Analysis to Assess the Relationship of MMSE Time Subscale Scores with AD Progression at 2-Year Follow- $U_{P}$ in Individuals with $\mathrm{MCl}$

\begin{tabular}{|c|c|c|}
\hline & \multicolumn{2}{|c|}{ AD Progression at Two-Year Follow-Up } \\
\hline & OR (95\% Cl) & $\mathbf{P}$ value \\
\hline \multicolumn{3}{|c|}{ One item model } \\
\hline \multicolumn{3}{|c|}{ MMSE time-season (S) } \\
\hline Model I & 0.611 (0.292 to I.278) & 0.191 \\
\hline Model 2 & $0.610(0.292$ to 1.276$)$ & 0.189 \\
\hline Model 3 & $0.710(0.329$ to 1.534$)$ & 0.384 \\
\hline \multicolumn{3}{|c|}{ MMSE time-year (Y) } \\
\hline Model I & $\mathrm{I} .434(0.274$ to $7.5 \mathrm{I} 8)$ & 0.670 \\
\hline Model 2 & $\mathrm{I} .45 \mathrm{I}(0.276$ to $7.62 \mathrm{I})$ & 0.660 \\
\hline Model 3 & $1.708(0.310$ to 9.394$)$ & 0.538 \\
\hline \multicolumn{3}{|c|}{ MMSE time-month (M) } \\
\hline Model I & $0.418(0.092$ to 1.902$)$ & 0.259 \\
\hline Model 2 & $0.423(0.093$ to 1.936$)$ & 0.268 \\
\hline Model 3 & $0.504(0.101$ to 2.512$)$ & 0.403 \\
\hline \multicolumn{3}{|c|}{ MMSE time-week (W) } \\
\hline Model I & $0.369(0.173$ to 0.786$)$ & 0.010 \\
\hline Model 2 & $0.369(0.172$ to 0.793$)$ & 0.011 \\
\hline Model 3 & $0.498(0.226$ to 1.098$)$ & 0.084 \\
\hline \multicolumn{3}{|c|}{ MMSE time-day (D) } \\
\hline Model I & $0.576(0.327$ to 1.014$)$ & 0.056 \\
\hline Model 2 & $0.582(0.329$ to 1.029$)$ & 0.063 \\
\hline Model 3 & 0.626 (0.347 to I.I29) & 0.120 \\
\hline \multicolumn{3}{|c|}{ Two items model with $\mathrm{W}$} \\
\hline \multicolumn{3}{|c|}{ MMSE time-SW } \\
\hline Model I & $0.506(0.303$ to 0.843$)$ & 0.009 \\
\hline Model 2 & $0.508(0.304$ to 0.848$)$ & 0.010 \\
\hline Model 3 & $0.618(0.362$ to 1.056$)$ & 0.078 \\
\hline \multicolumn{3}{|c|}{ MMSE time-YW } \\
\hline Model I & 0.463 (0.233 to 0.918$)$ & 0.027 \\
\hline Model 2 & $0.465(0.232$ to 0.929$)$ & 0.030 \\
\hline Model 3 & $0.618(0.301$ to 1.268$)$ & 0.189 \\
\hline \multicolumn{3}{|c|}{ MMSE time-MW } \\
\hline Model I & $0.400(0.205$ to 0.779$)$ & 0.007 \\
\hline Model 2 & $0.402(0.205$ to 0.787$)$ & 0.008 \\
\hline Model 3 & 0.514 (0.255 to 1.037$)$ & 0.063 \\
\hline \multicolumn{3}{|c|}{ MMSE time-WD } \\
\hline Model I & $0.526(0.34 \mathrm{I}$ to 0.812$)$ & 0.004 \\
\hline Model 2 & 0.527 (0.339 to 0.818$)$ & 0.004 \\
\hline
\end{tabular}

(Continued)
Table 4 (Continued).

\begin{tabular}{|c|c|c|}
\hline & \multicolumn{2}{|c|}{ AD Progression at Two-Year Follow-Up } \\
\hline & OR $(95 \% \mathrm{Cl})$ & $P$ value \\
\hline Model 3 & $0.603(0.382$ to 0.953$)$ & 0.030 \\
\hline \multicolumn{3}{|c|}{ Three items model with WD } \\
\hline \multicolumn{3}{|c|}{ MMSE time-SWD } \\
\hline Model I & 0.572 (0.398 to 0.822$)$ & 0.003 \\
\hline Model 2 & $0.574(0.398$ to 0.827$)$ & 0.003 \\
\hline Model 3 & $0.649(0.443$ to 0.951$)$ & 0.026 \\
\hline \multicolumn{3}{|c|}{ MMSE time-YWD } \\
\hline Model I & $0.564(0.372$ to 0.856$)$ & 0.007 \\
\hline Model 2 & $0.565(0.37 \mid$ to 0.863$)$ & 0.008 \\
\hline Model 3 & $0.650(0.419$ to 1.009$)$ & 0.055 \\
\hline \multicolumn{3}{|c|}{ MMSE time-MWD } \\
\hline Model I & $0.536(0.356$ to 0.806$)$ & 0.003 \\
\hline Model 2 & $0.536(0.354$ to 0.812$)$ & 0.003 \\
\hline Model 3 & $0.608(0.394$ to 0.938$)$ & 0.024 \\
\hline \multicolumn{3}{|c|}{ Four items model with S(or M)WD } \\
\hline \multicolumn{3}{|c|}{ MMSE time-SYWD } \\
\hline Model I & $0.600(0.422$ to 0.853$)$ & 0.004 \\
\hline Model 2 & $0.602(0.422$ to 0.858$)$ & 0.005 \\
\hline Model 3 & $0.682(0.470$ to 0.989$)$ & 0.043 \\
\hline \multicolumn{3}{|c|}{ MMSE time-SMWD } \\
\hline Model I & $0.589(0.418$ to 0.829$)$ & 0.002 \\
\hline Model 2 & 0.591 ( 0.418 to 0.834$)$ & 0.003 \\
\hline Model 3 & $0.66 \mathrm{I}(0.46 \mathrm{I}$ to 0.947$)$ & 0.024 \\
\hline \multicolumn{3}{|c|}{ MMSE time-YMWD } \\
\hline Model I & 0.568 (0.383 to 0.843$)$ & 0.005 \\
\hline Model 2 & $0.570(0.382$ to 0.849$)$ & 0.006 \\
\hline Model 3 & $0.649(0.427$ to 0.986$)$ & 0.043 \\
\hline
\end{tabular}

Notes: Model I did not include any covariates. Model 2 included age, sex, and education as covariates. Model 3 included age, sex, education, and CDR-SB score as covariates.

Abbreviations: OR, odds ratio; $\mathrm{Cl}$, confidence interval.

growing, and the ADNI study included comprehensive measures of biomarkers, such as MRI, FDG, and amyloid PET. Outside the practical clinical setting, further research using biomarker changes as outcome variables in addition to clinical AD conversion is required. Finally, we used only 2-year follow-up data to investigate the earliest predictors of $\mathrm{AD}$ conversion within a short period. However, further studies with a longer follow-up period are required. 


\section{Conclusion}

Our findings emphasize the importance of assessing orientation and construction domains to identify subjects at high risk of $\mathrm{AD}$ conversion among elderly people whose memory function is already impaired. In terms of simplicity, rapid administration, and ease of interpretation, MMSE subscales of memory, orientation, and construction could be useful screening tools for predicting conversion to $\mathrm{AD}$ from MCI in practical clinical settings.

\section{Acknowledgments}

Data used in preparation of this article were obtained from the Alzheimer's Disease Neuroimaging Initiative (ADNI) database (adni.loni.usc.edu). As such, the investigators within the ADNI contributed to the design and implementation of ADNI and/or provided data but did not participate in analysis or writing of this report. A complete listing of ADNI investigators can be found at: http://adni. loni.usc.edu/wp-content/uploads/how to_apply/ADNI Acknowledgement List.pdf.

Data collection and sharing for this project was funded by the Alzheimer's Disease Neuroimaging Initiative (ADNI) (National Institutes of Health Grant U01 AG024904) and DOD ADNI (Department of Defense award number W81XWH-12-2-0012). ADNI is funded by the National Institute on Aging, the National Institute of Biomedical Imaging and Bioengineering, and through generous contributions from the following: AbbVie, Alzheimer's Association; Alzheimer's Drug Discovery Foundation; Araclon Biotech; BioClinica, Inc.; Biogen; Bristol-Myers Squibb Company; CereSpir, Inc.; Cogstate; Eisai Inc.; Elan Pharmaceuticals, Inc.; Eli Lilly and Company; EuroImmun; F. Hoffmann-La Roche Ltd and its affiliated company Genentech, Inc.; Fujirebio; GE Healthcare; IXICO Ltd.; Janssen Alzheimer Immunotherapy Research \& Development, LLC.; Johnson \& Johnson Pharmaceutical Research \& Development LLC.; Lumosity; Lundbeck; Merck \& Co., Inc.; Meso Scale Diagnostics, LLC.; NeuroRx Research; Neurotrack Technologies; Novartis Pharmaceuticals Corporation; Pfizer Inc.; Piramal Imaging; Servier; Takeda Pharmaceutical Company; and Transition Therapeutics. The Canadian Institutes of Health Research is providing funds to support ADNI clinical sites in Canada. Private sector contributions are facilitated by the Foundation for the National Institutes of Health (www. fnih.org). The grantee organization is the Northern
California Institute for Research and Education, and the study is coordinated by the Alzheimer's Therapeutic Research Institute at the University of Southern California. ADNI data are disseminated by the Laboratory for Neuro Imaging at the University of Southern California. This research was also supported by Hallym University Research Fund (HURF-2019-62).

\section{Disclosure}

The authors report no conflicts of interest in this work.

\section{References}

1. Petersen RC, Smith GE, Waring SC, Ivnik RJ, Tangalos EG, Kokmen E. Mild cognitive impairment: clinical characterization and outcome. Arch Neurol. 1999;56(3):303-308. doi:10.1001/archneur.56.3.303

2. Manly JJ, Tang MX, Schupf N, Stern Y, Vonsattel JP, Mayeux R. Frequency and course of mild cognitive impairment in a multiethnic community. Ann Neurol. 2008;63(4):494-506. doi:10.1002/ana.21326

3. Petersen RC, Roberts RO, Knopman DS, et al. Mild cognitive impairment: ten years later. Arch Neurol. 2009;66(12):1447-1455. doi:10.1001/archneurol.2009.266

4. Ganguli M, Dodge HH, Shen C, DeKosky ST. Mild cognitive impairment, amnestic type: an epidemiologic study. Neurology. 2004;63 (1):115-121. doi:10.1212/01.WNL.0000132523.27540.81

5. Spasov S, Passamonti L, Duggento A, Lio P, Toschi N. Alzheimer's disease neuroimaging I. A parameter-efficient deep learning approach to predict conversion from mild cognitive impairment to alzheimer's disease. NeuroImage. 2019;189:276-287. doi:10.1016/j. neuroimage.2019.01.031

6. Gainotti G, Quaranta D, Vita MG, Marra C. Neuropsychological predictors of conversion from mild cognitive impairment to Alzheimer's disease. $J$ Alzheimers Dis. 2014;38(3):481-495. doi:10.3233/JAD-130881

7. Pereira T, Ferreira FL, Cardoso S, et al. Neuropsychological predictors of conversion from mild cognitive impairment to Alzheimer's disease: a feature selection ensemble combining stability and predictability. BMC Med Inform Decis Mak. 2018;18(1):137. doi:10.1186/ s12911-018-0710-y

8. Tabert MH, Manly JJ, Liu X, et al. Neuropsychological prediction of conversion to Alzheimer disease in patients with mild cognitive impairment. Arch Gen Psychiatry. 2006;63(8):916-924. doi:10.1001/archpsyc.63.8.916

9. Liu Y, Paajanen T, Zhang Y, et al. Analysis of regional MRI volumes and thicknesses as predictors of conversion from mild cognitive impairment to Alzheimer's disease. Neurobiol Aging. 2010;31 (8):1375-1385. doi:10.1016/j.neurobiolaging.2010.01.022

10. Chetelat G, Desgranges B, de la Sayette V, Viader F, Eustache F, Baron JC. Mild cognitive impairment: can FDG-PET predict who is to rapidly convert to Alzheimer's disease? Neurology. 2003;60 (8):1374-1377. doi:10.1212/01.WNL.0000055847.17752.E6

11. Jack CR Jr, Petersen RC, Xu YC, et al. Prediction of AD with MRIbased hippocampal volume in mild cognitive impairment. Neurology. 1999;52(7):1397-1403. doi:10.1212/WNL.52.7.1397

12. Farlow MR, He Y, Tekin S, Xu J, Lane R, Charles HC. Impact of APOE in mild cognitive impairment. Neurology. 2004;63(10):18981901. doi:10.1212/01.WNL.0000144279.21502.B7

13. Blom ES, Giedraitis V, Zetterberg H, et al. Rapid progression from mild cognitive impairment to Alzheimer's disease in subjects with elevated levels of tau in cerebrospinal fluid and the APOE epsilon4/ epsilon4 genotype. Dement Geriatr Cogn Disord. 2009;27(5):458464. doi:10.1159/000216841 
14. Petersen RC, Smith GE, Ivnik RJ, et al. Apolipoprotein E status as a predictor of the development of Alzheimer's disease in memoryimpaired individuals. JAMA. 1995;273(16):1274-1278. doi:10.1001/ jama.1995.03520400044042

15. Samtani MN, Raghavan N, Shi Y, et al. Disease progression model in subjects with mild cognitive impairment from the Alzheimer's disease neuroimaging initiative: CSF biomarkers predict population subtypes. Br J Clin Pharmacol. 2013;75(1):146-161. doi:10.1111/ j.1365-2125.2012.04308.x

16. De Meyer G, Shapiro F, Vanderstichele H, et al. Diagnosis-independent Alzheimer disease biomarker signature in cognitively normal elderly people. Arch Neurol. 2010;67(8):949-956. doi:10.1001/ archneurol.2010.179

17. Fagan AM, Roe CM, Xiong C, Mintun MA, Morris JC, Holtzman DM. Cerebrospinal fluid tau/beta-amyloid(42) ratio as a prediction of cognitive decline in nondemented older adults. Arch Neurol. 2007;64 (3):343-349. doi:10.1001/archneur.64.3.noc60123

18. Smach MA, Charfeddine B, Ben Othman L, et al. Evaluation of cerebrospinal fluid tau/beta-amyloid(42) ratio as diagnostic markers for Alzheimer disease. Eur Neurol. 2009;62(6):349-355. doi: $10.1159 / 000241881$

19. Gomar JJ, Bobes-Bascaran MT, Conejero-Goldberg C, Davies P, Goldberg TE. Alzheimer's disease neuroimaging I. Utility of combinations of biomarkers, cognitive markers, and risk factors to predict conversion from mild cognitive impairment to alzheimer disease in patients in the Alzheimer's disease neuroimaging initiative. Arch Gen Psychiatry. 2011;68(9):961-969. doi:10.1001/archgenpsychiatry.2011.96

20. Davatzikos C, Bhatt P, Shaw LM, Batmanghelich KN, Trojanowski JQ. Prediction of MCI to AD conversion, via MRI, CSF biomarkers, and pattern classification. Neurobiol Aging. 2011;32(12):2322 e2319e2327. doi:10.1016/j.neurobiolaging.2010.05.023

21. Risacher SL, Saykin AJ. Neuroimaging and other biomarkers for Alzheimer's disease: the changing landscape of early detection. Annu Rev Clin Psychol. 2013;9:621-648. doi:10.1146/annurevclinpsy-050212-185535

22. Qin Y, Tian Y, Han H, et al. Risk classification for conversion from mild cognitive impairment to Alzheimer's disease in primary care. Psychiatry Res. 2019;278:19-26. doi:10.1016/j.psychres.2019.05.027

23. Nakata E, Kasai M, Kasuya M, et al. Combined memory and executive function tests can screen mild cognitive impairment and converters to dementia in a community: the Osaki-Tajiri project. Neuroepidemiology. 2009;33(2):103-110. doi:10.1159/000222092

24. Daly E, Zaitchik D, Copeland M, Schmahmann J, Gunther J, Albert M. Predicting conversion to Alzheimer disease using standardized clinical information. Arch Neurol. 2000;57(5):675-680. doi:10.1001/ archneur.57.5.675

25. Kim JW, Byun MS, Sohn BK, et al. Clinical dementia rating orientation score as an excellent predictor of the progression to Alzheimer's disease in mild cognitive impairment. Psychiatry Investig. 2017;14 (4):420-426. doi:10.4306/pi.2017.14.4.420

26. Mossello E, Boncinelli M. Mini-mental state examination: a 30-year story. Aging Clin Exp Res. 2006;18:271-273. doi:10.1007/BF03324660

27. Chow TW, Hynan LS, Lipton AM. MMSE scores decline at areater rate in frontotemporal degeneration than in AD. Dement Geriatr Cogn Disord. 2006;22(3):194-199. doi:10.1159/000094870

28. Ala TA, Hughes LF, Kyrouac GA, Ghobrial MW, Elble RJ. The minimental state exam may help in the differentiation of dementia with Lewy bodies and Alzheimer's disease. Int J Geriatr Psychiatry. 2002;17(6):503-509. doi:10.1002/gps.550

29. Chehrehnegar N, Nejati V, Shati M, et al. Early detection of cognitive disturbances in mild cognitive impairment: a systematic review of observational studies. Psychogeriatrics. 2020;20(2):212-228. doi: $10.1111 /$ psyg. 12484
30. Petersen RC. Mild cognitive impairment as a diagnostic entity. J Intern Med. 2004;256(3):183-194. doi:10.1111/j.1365-2796.2004.01388.x

31. Rosen WG, Mohs RC, Davis KL. A new rating scale for Alzheimer's disease. Am J Psychiatry. 1984;141(11):1356-1364.

32. McKhann G, Drachman D, Folstein M, Katzman R, Price D, Stadlan EM. Clinical diagnosis of Alzheimer's disease: report of the NINCDS-ADRDA work group under the auspices of department of health and human services task force on Alzheimer's disease. Neurology. 1984;34(7):939-944. doi:10.1212/WNL.34.7.939

33. Backman L, Small BJ, Fratiglioni L. Stability of the preclinical episodic memory deficit in Alzheimer's disease. Brain. 2001;124(Pt 1):96-102. doi:10.1093/brain/124.1.96

34. Tierney MC, Szalai JP, Snow WG, et al. Prediction of probable Alzheimer's disease in memory-impaired patients: a prospective longitudinal study. Neurology. 1996;46(3):661-665. doi:10.1212/ WNL.46.3.661

35. Ashford JW, Kolm P, Colliver JA, Bekian C, Hsu LN. Alzheimer patient evaluation and the mini-mental state: item characteristic curve analysis. $J$ Gerontol. 1989;44(5):P139-P146. doi:10.1093/geronj/44.5.P139

36. Guerrero-Berroa E, Luo X, Schmeidler J, et al. The MMSE orientation for time domain is a strong predictor of subsequent cognitive decline in the elderly. Int J Geriatr Psychiatry. 2009;24(12):14291437. doi: $10.1002 / \mathrm{gps} .2282$

37. Lee DY, Youn JC, Choo IH, et al. Combination of clinical and neuropsychologic information as a better predictor of the progression to alzheimer disease in questionable dementia individuals. Am J Geriatr Psychiatry. 2006;14(2):130-138. Doi:10.1097/01. JGP.0000192487.58426.d2

38. Tounsi H, Deweer B, Ergis AM, et al. Sensitivity to semantic cuing: an index of episodic memory dysfunction in early Alzheimer disease. Alzheimer Dis Assoc Disord. 1999;13(1):38-46. doi:10.1097/ 00002093-199903000-00006

39. Giannakopoulos P, Gold G, Duc M, Michel JP, Hof PR, Bouras C. Neural substrates of spatial and temporal disorientation in Alzheimer's disease. Acta Neuropathol. 2000;100(2):189-195. doi: $10.1007 / \mathrm{s} 004019900166$

40. Hirono N, Mori E, Ishii K, et al. Hypofunction in the posterior cingulate gyrus correlates with disorientation for time and place in Alzheimer's disease. J Neurol Neurosurg Psychiatry. 1998;64 (4):552-554. doi:10.1136/jnnp.64.4.552

41. Ala TA, Hughes LF, Kyrouac GA, Ghobrial MW, Elble RJ. Pentagon copying is more impaired in dementia with Lewy bodies than in Alzheimer's disease. J Neurol Neurosurg Psychiatry. 2001;70 (4):483-488. doi:10.1136/jnnp.70.4.483

42. Mitolo M, Salmon DP, Gardini S, Galasko D, Grossi E, Caffarra P. The new Qualitative Scoring MMSE Pentagon Test (QSPT) as a valid screening tool between autopsy-confirmed dementia with Lewy bodies and Alzheimer's disease. J Alzheimers Dis. 2014;39(4):823832. doi:10.3233/JAD-131403

43. Crum RM, Anthony JC, Bassett SS, Folstein MF. Population-based norms for the mini-mental state examination by age and educational level. JAMA. 1993;269(18):2386-2391. doi:10.1001/jama.1993.035 00180078038

44. Monsch AU, Foldi NS, Ermini-Funfschilling DE, et al. Improving the diagnostic accuracy of the mini-mental state examination. Acta Neurol Scand. 1995;92(2):145-150. doi:10.1111/j.1600-0404.1995. tb01029.x 


\section{Publish your work in this journal}

Neuropsychiatric Disease and Treatment is an international, peerreviewed journal of clinical therapeutics and pharmacology focusing on concise rapid reporting of clinical or pre-clinical studies on a range of neuropsychiatric and neurological disorders. This journal is indexed on PubMed Central, the 'PsycINFO' database and CAS, and is the official journal of The International Neuropsychiatric Association (INA). The manuscript management system is completely online and includes a very quick and fair peer-review system, which is all easy to use. Visit http://www.dovepress.com/testimonials.php to read real quotes from published authors.

Submit your manuscript here: https://www.dovepress.com/neuropsychiatric-disease-and-treatment-journal 